\title{
Cantaré e cantaría / cantarei e cantaria: usos retos e deslocados
}

Palavras chave: referenciação futura, sistema vetorial, relações temporais, usos retos, usos deslocados, valores modais.

\section{Introdução}

Este artigo visa contribuir para a descrição do conceito da futuridade e uma reflexão aprofundada sobre o funcionamento das formas de marcação de valores de tempo futuro em português europeu contemporâneo (PE) e em espanhol europeu contemporâneo (ES). Nela pretendemos discernir como funcionam as formas portuguesas cantarei e cantaria nos seus usos deslocados em contraste com as formas espanholas cantaré e cantaría com o objetivo de contribuir para a descrição contrastiva dos valores temporais e modais que as respetivas formas das duas línguas evidenciam.

O ponto de partida para este artigo é a hipótese inicial se a proposta do sistema vetorial de Rojo e Veiga, explicando e simbolizando com as fórmulas vetoriais o panorama temporal de espanhol, poderia ser adequado para descrever os processos de deslocação que ocorrem no sistema temporal de português.

Esta hipótese de análise contrastiva assenta nas seguintes considerações:

(i) tanto em PE como em ES, os recursos de que os falantes dispõem para expressar o tempo ou processar a informação temporal são de natureza diversa: para além da flexão verbal, que permite distinguir morfologicamente diferentes tempos gramaticais, há ainda considerar as expressões adverbiais temporais e os conectores frásicos que introduzem orações subordinadas temporais; 
(ii) todas as línguas naturais dispõem de várias estratégias para construir a referência a um estado de coisas que é posterior ao momento da enunciação'; (iii) em termos dos tempos gramaticais tanto em PE como em ES o valor de posterioridade pode estar construído a partir dos tempos gramaticais que possuem marcas específicas de tempo gramatical de futuro ${ }^{2}$;

(iv) as formas linguísticas interpretáveis como marcadoras de posterioridade em PE e em ES são sobretudo marcas modais. Quanto a esta última consideração, recorde-se que a evolução diacrónica das formas de futuro passa por fases precisas, caracterizadas por valores de diferente natureza (Bybee et al., 1994). Assim, as diferenças no uso das várias formas são explicadas justamente em termos do seu grau de retenção de antigos usos modais ou aspectuais e de especialização no uso de "simple future or prediction" e da existência de usos modais que derivam de um desenvolvimento semântico tardio deste valor temporal. Deste este ponto de vista, a propriedade mais saliente do futuro românico é a sua disponibilidade para expressar valores modais que coexistem com a função temporal. Um destes usos, denotador do valor modal, é o uso epistémico que expressa uma predição sobre uma situação presente, que é interpretada como uma expressão de probabilidade.

A análise dos matizes temporais e modais basear-se-á nas formas cantarei e cantaria (PT), cantaré e cantaría (ES) que nos seus usos retos implicam uma referenciação temporal de posterioridade. Realizar-se-á dentro dos pressupostos teóricos de Rojo e Veiga (2000) que se baseiam na perspetiva de Bello (1841).

\section{De Bello a Rojo e Veiga}

Andrés Bello foi o primeiro a dar uma visão geral dos valores temporais do verbo espanhol em sua Análisis ideológico de los tiempos de conjugación castellana (1841). Este trabalho foi publicado pela primeira vez em 1841, mas segundo o mesmo Bello, foi escrito mais de trinta anos antes. Mais tarde, a Análisis foi integrada sem grandes modificações em sua Gramática de la lengua castellana destinada al uso de los americanos (1847). Imediatamente depois da publicação da Gramática se criticaram alguns aspetos do trabalho juvenil de Bello, particularmente a simetria excessiva do seu sistema. O seu tratamento do verbo, que se inscreve dentro da tradição racionalista francesa, contrasta, de alguma forma, com o espírito geral da sua Gramática. Mas o seu sistema não deve ser considerado como uma criação apriorística, nem tem a intenção de ter a

1 Cf. Markič \& Correia (2013)

2 Cf. Oliveira (2003) 
validade universal. Baseia-se nas noções fundamentais de anterioridade, simultaneidade e posterioridade, por um lado e, por outro, na observação dos fatos linguísticos de uma língua particular. Essencialmente, parece que ainda hoje as concepções de Bello seguem válidas, e as ideias básicas podem servir como um ponto de partida para uma análise da temporalidade verbal.

Entre os estudos modernos dedicados a este problema deve-se ressaltar o trabalho de Rojo e Veiga (2000). Com base, como Bello, nas três noções temporais básicas e adotando o sistema vetorial de Bull (1968), com algumas modificações, estes autores propõem uma descrição estrutural dos tempos gramaticais espanhóis, onde cada forma está relacionada, direta ou indiretamente, com o eixo principal de referência, chamado a origem (o).

\section{Rojo e Veiga: relações temporais e usos deslocados}

Para tratar as relações temporais e analisar o conceito de usos deslocados abordaremos aqui, como se disse e embora sem pormenorizar todos os seus fundamentos teóricos, a proposta de Rojo e Veiga (2000).

Para estes autores o tempo linguístico é bidirecional e, por tanto, um acontecimento linguístico pode ser considerado anterior, simultâneo ou posterior ao outro. Seguindo a linha de Bull (1960) e Rojo (2000: 2876), podemos contemplar estas relações temporais como vetores $(\mathrm{V})$ e concordar em que o símbolo $-\mathrm{V}$ simboliza a anterioridade, $\mathrm{oV}$ a simultaneidade, $\mathrm{e}+\mathrm{V}$ a posterioridade. $\mathrm{O}$ ponto central de todas as relações temporais chama-se $\mathrm{O}$ (e significa 'origem'). Assim, as três relações, possíveis já desde início, dum acontecimento linguístico com um ponto zero são simbolizáveis mediante as fórmulas $\mathrm{O}-\mathrm{V}$ para $\mathrm{o}$ acontecimento anterior à origem (vetor negativo $=$ anterioridade), OoV para o simultâneo à origem (vetor zero = simultaneidade), e $\mathrm{O}+\mathrm{V}$ para o posterior à origem (vetor positivo = posterioridade). $\mathrm{A}$ aparente existência de relações temporais mais complexas não procede do aumento dessas possibilidades iniciais, mas da sua encadeação numa série teoricamente ilimitada de conjuntos. Dito de outra forma, qualquer ponto, orientado com respeito à origem, se pode tornar uma referência em relação a qual se situa outro acontecimento que é, assim, orientado diretamente para a referência e apenas indiretamente com respeito à origem. Assim, Rojo e Veiga apresentam as fórmulas $(\mathrm{O}-\mathrm{V})-\mathrm{V}$, $(\mathrm{O}-\mathrm{V}) \mathrm{oV}$ e $(\mathrm{O}-\mathrm{V})+\mathrm{V}$, que correspondem a acontecimentos que são, respetivamente, anterior, simultâneo e posterior a outro acontecimento que a sua vez é anterior à origem. 
Em relação com o conceito de deslocação e usos deslocados podemos confirmar que a deslocação pode ser concebida como uma reorganização dos conteúdos temporais que aporta uma reorganização paralela dos conteúdos modais. Assim, explicam Rojo e Veiga (2000: 2894) que a 'deslocação temporal' das formas verbais pode ser vista como um mecanismo mediante o qual as formas adquirem valores adicionais. Defendem estes autores que é necessário diferenciar, para todas as formas, entre um 'valor reto' e 'valores deslocados' que aparecem sistematicamente como consequência da expressão de um valor temporal distinto do reto.

\subsection{Realização básica do conteúdo temporal cantaré (ES) / cantarei (PT) - valores retos}

1. Mi primo estudiará filología clásica³.

2. O meu primo estudará filología clássica.

Tanto em ES como em PT as expressões verbais que correspondem à realização de um dos conteúdos temporais mais simples que se assenta numa orientação medida diretamente desde o ponto origem $(\mathrm{O})$ são as formas cantaré $e$ cantarei: tendo em vista a orientação temporal primária diretamente enfocada desde o centro de referências do sistema, estas formas expressam as relações de posterioridade. A fórmula para as duas formas, tanto em ES e em PT, seria $(\mathrm{O}+\mathrm{V})$. São reconhecíveis em circunstâncias de total independência sintática e sem necessidade de que exista nenhum tipo de indicador temporal no contexto, tal como adverbial temporal ou outro elemento linguístico que permita localizar cronologicamente o processo verbal.

\subsection{Realização básica do conteúdo temporal cantaría (ES) / cantaria (PT) - valores retos}

Neste ponto, oferece-se a exame a relação temporal de posterioridade dentro do vetor original negativo. As formas cantaría e cantaria expressam relações temporais bivetoriais que incluem sempre um vetor originário negativo. $\mathrm{O}$ vetor primário das formas cantaría e cantaria em ambas as línguas, é o vetor positivo, simbolizando a posterioridade. Assim, em ambas as línguas em questão, podemos observar, como propõem Rojo e Veiga (2000: 2884) o que ocorre entre cantaré e cantaría e cantarei e cantaria: todas estas formas são os paradigmas que expressam primariamente posterioridade; a diferença entre elas consiste

3 Os exemplos são meus. 
em que a primeira (cantaré, cantarei) o faz em relação à origem e a segunda (cantaría, cantaria), porém, com respeito a um ponto anterior à origem:

3. Dice que su primo estudiará filología clásica. $\quad \mathrm{O}+\mathrm{V}$

4. Dijo que su primo estudiaría filología clásica. $\quad(\mathrm{O}-\mathrm{V})+\mathrm{V}$

5. Diz que o seu primo estudará filología clássica. $\quad \mathrm{O}+\mathrm{V}$

6. Disse o seu primo estudaria filología clássica. $\quad(\mathrm{O}-\mathrm{V})+\mathrm{V}$

Em (3) e (5) trata-se da realização básica do conteúdo temporal, simbolizável pela fórmula $\mathrm{O}+\mathrm{V}$. É óbvio, como se disse já pouco atrás, que no caso da forma cantaría, cantaria que se apresentam nos exemplos (4) e (6), o decisivo que estabelece o lugar desta forma verbal no sistema temporal do espanhol, igual que no sistema temporal do português, é a expressão duma situação posterior a uma referência anterior à origem e não a orientação desta situação com relação à origem.

\subsection{Primeiro caso de deslocação temporal no indicativo espanhol e português}

O mecanismo do primeiro caso geral de deslocação abrange a aquisição de um valor modal de incerteza por parte das formas em cujo valor reto intervém um vetor de posterioridade.

Assim, no sentido temporal, em espanhol,

- cantaré pode expressar a relação 'presente' e

- cantaría pode expressar as relações 'pretérito' e 'co-pretérito'.

O valor modal adquirido é o valor de incerteza.

Vejamos, à base dos exemplos apresentados, como funciona o mecanismo de deslocação:

7. Ahora estará estudiando en su cuarto. - incerteza, probabilidade no presente

8. En aquel momento tendría treinta años. - incerteza ou suposição no passado

9. Agora estará a estudar no seu quarto. - incerteza, probabilidade no presente

10. Naquela altura teria trinta anos. - incerteza ou suposição no passado

Em (7) e (9) apresenta-se o uso do futuro pelo presente e nestes exemplos observa-se que o vetor de posterioridade é sustituído por outro de simultaneidade. Esta deslocação provoca um desajuste entre o valor central (posterioridade) das formas estará (ES) e estará (PT) e a relação temporal expressada (simultaneidade) pelas mesmas. Como consequência deste desajuste aparece um valor modal adicional que é o valor de incerteza, probabilidade no presente. 
Nos exemplos (8) e (10), ou seja, tanto em ES como em PT, encontramos o mesmo fenómeno de deslocação e detectamos os mesmos efeitos: o vetor de posterioridade é sustituído por outro de simultaneidade, acrescenta-se o valor modal de incerteza ou suposição no passado.

Ilustrando o primeiro caso de deslocação com as fórmulas vetoriais, propostas por Rojo e Veiga (2000: 2913), vemos que, substituindo nas realizações básicas mencionadas o vetor de posterioridade por um de simultaneidade ou, em alguns casos (pos-pretérito - pretérito), suprimindo-o, tanto em ES como em PT, obtemos as seguintes correspondências:

$\begin{array}{lll}\mathrm{O}+\mathrm{V} & \mathrm{OoV} \\ \text { futuro } & \text { presente } \\ \text { cantaré } & \text { canto } \\ \text { cantarei } & \text { canto } \\ (\mathrm{O}-\mathrm{V})+\mathrm{V} & \mathrm{O}-\mathrm{V} \\ \text { pos-pretérito } & \text { pretérito } \\ \text { cantaría } & \text { canté } \\ \text { cantaria } & \text { cantei } \\ (\mathrm{O}-\mathrm{V})+\mathrm{V} & (\mathrm{O}-\mathrm{V}) \mathrm{oV} \\ \text { pos-pretérito } & \text { co-pretérito } \\ \text { cantaría } & \text { cantaba } \\ \text { cantaria } & \text { cantava }\end{array}$

\section{Esquema (1)}

No caso denominado por Rojo e Veiga o primeiro tipo de deslocacação, podemos observar que em ambas as línguas existem empregos do futuro do indicativo que expressam referência temporal não-futura: o futuro, tanto quando expressa as relações de posterioridade medidas diretamente desde o ponto origem $(\mathrm{O})$ (cantaré e cantarei ) como quando expressam a relação temporal de posterioridade dentro do vetor original negativo e em relação a um ponto anterior à origem (cantaría, cantaria), pode servir para referir uma inferência relativa a uma situação presente ou passada respetivamente. O domínio conceptual em causa é então o do epistémico. Trata-se do mais comum dos usos não-futurais da forma, sendo a sua frequência particularmente alta em variedades coloquiais. 


\subsection{Segundo caso de deslocação temporal no indicativo espanhol e português}

O mecanismo do segundo caso geral de deslocação abrange a aquisição de um valor modal de irrealidade por parte das formas verbais em cujo valor reto intervém algum vetor de anterioridade unido a algum vetor de posterioridade. Esta combinação vetorial encontra a sua realização na forma cantaría (ES) e, como veremos, em português, na forma cantaria (PT). Assim, a forma cantaría pode ser utilizada para expressar a mesma relação temporal que constitui o uso reto de canto. Também em português se nota que a forma cantaria expressa a mesma relação temporal que é a relação do uso reto de canto (PT). O valor modal adquirido nesse processo de deslocação é o valor modal de irrealidade que adquirem as formas em ambas as línguas.

11. En estos momentos estaría encantado en la playa. - valor modal de irrealidade no presente

12. (Se quisesse passar no exame), nestes momentos estudaria no meu quarto. - valor modal de irrealidade no presente

Estaría encantado implica no estoy, estudaria implica que não estuda. Os exemplos são aparentados na medida em que se pode inferir que os eventos descritos nas orações não se estão a realizar. O essencial, no sentido temporal, é o facto de que a relação temporal efetivamente expressada nestes casos é 'presente'. Em ambas as formas, tanto em forma de espanhol como em forma de português, ficam suprimidos os vetores originários de anterioridade e os primários de posterioridade. Mediante o processo de deslocação se cria o conteúdo modal de irrealidade que nos exemplos acima citados marcam as formas em questão.

Ilustra-se no esquema (2) o segundo caso de deslocação com as fórmulas vetoriais, propostas por Rojo e Veiga (2000: 2914). Acrescentam-se as formas em PT:

$(\mathrm{O}-\mathrm{V})+\mathrm{V}$

pos-pretérito

cantaría

cantaria

Esquema (2)

\section{$\mathrm{OoV}$}

presente

canto

canto 


\section{Notas conclusivas}

O ponto de partida para este artigo era a hipótese inicial se a proposta do sistema vetorial de Rojo e Veiga, explicando e simbolizando com as fórmulas vetoriais o panorama temporal de espanhol, poderia ser adequado para descrever os processos de deslocação que ocorrem no sistema temporal de português. Realizada uma análise, podemos verificar que a resposta à nossa hipótese inicial é positiva. Tanto em ES como em PT encontramos os dois casos de deslocação com as respetivas consequências, como proposto na teoria de Rojo e Veiga.

Verificamos com Rojo e Veiga (2000: 2895) que o primeiro caso de deslocação, como descrito pelos autores, conducente a matizes modais de incerteza, é exclusivo, tanto em ES como em PT, daquelas formas verbais de indicativo em cujo valor temporal reto intervém obrigatoriamente algum vetor de posterioridade. Estas formas são cantaré, cantaria (ES) / cantarei, cantaria (PT). Mediante esta deslocação fica suprimido o vetor de posterioridade e substituise com o vetor de simultaneidade. Em quanto ao segundo caso de deslocação, conducente a matizes modais de irrealidade, esta pode aparecer em certas formas indicativas em cujo valor temporal reto intervém obrigatoriamente algum vetor originário de anterioridade, em concreto, nas formas indicativas cantaría (ES) / cantaria (PT).

\section{Bibliografia}

Bello, Andrés (1847/1988): Gramática de la lengua castellana destinada al uso de los americanos, I, II con las notas de Rufino José Cuervo. Estudio y edición de Ramón Trujillo. Madrid: Arco Libros.

Bull, Wiliam E. (1968): Time, Tense and the Verb. A Study in Theoretical and Applied Linguistics, with Particular Attention to Spanish. Berkeley: University of California Press.

Bybee, Joan et. altri (1994): The Evolution of Grammar. Tense, Aspect, and Modality in the Languages of the World. Chicago: University of Chicago Press.

Markič, Jasmina \& Clara Nunes Correia (ur.) (2013): Descrições e Contrastes - Tópicos de Gramática Portuguesa com Exemplos Contrastivos Eslovenos/ Opisi in primerjave. Poglavja iz slovnice portugalskega jezika s kontrastivnimi ponazoritvami $v$ slovenščini. Ljubljana: Znanstvena založba Filozofske fakultete. 
Oliveira, Fátima (2003): «Tempo e aspecto». Em: Mateus, M. Helena et al. Gramática da Lingua Portuguesa ( ${ }^{\mathrm{a}}$ ed.). Lisboa, Caminho, 129-178.

Rojo, Guillermo e Veiga, Alexandre (2000): «El tiempo verbal. Los tiempos simples». Em: Bosque, Ignacio e Demonte, Violeta (eds.) (2000): Gramática descriptiva de la lengua española. Madrid: Espasa, 2867-2934. 
Blažka Müller Pograjc

University of Ljubljana

\section{Cantaré and cantaría / cantarei and cantaria: straight and dislocated uses}

Keywords: Future reference, vectorial system, temporal relations, straight uses, dislocated uses, modal concepts.

In this article we contrast the Spanish and Portuguese future and conditional, as well as the straight and dislocated uses of these verb forms in these two languages, and observe that the vector concept, developed and proposed for the Spanish language by the Spanish linguists Rojo and Veiga, can be adapted for the description of these linguistic phenomena in both languages

The first case of the dislocation (migration for Bull (1968)), as described by the linguists, leading to modal concepts of uncertainty, is unique, both in ES and in PT, to those indicative verb forms in which straight time value obligatorily intersects some vector of posteriority. These forms are cantaré, cantaría / cantarei, cantaria and their corresponding composite forms. Through this dislocation, the vector of posteriority is suppressed and replaced with the vector of simultaneity. Considering the second case of the dislocation leading to modal concept of irreality, this may appear in that certain indicative forms in which straight time value obligatorily acquires some vector of anteriority, in particular, in the indicative forms cantaría / cantaria. 
Blažka Müller Pograjc

Univerza v Ljubljani

\section{Cantaré in cantaría / cantarei in cantaria: primarne in dislocirane rabe}

Ključne besede: prihodnostna referenca, vektorski sistem, časovna razmerja, primarne rabe, dislocirane rabe, modalne vrednosti

V pričujočem zapisu, ki kontrastira portugalski in španski futur ter pogojnik in njune primarne ter dislocirane rabe, avtorica ugotavlja, da je za opis teh jezikovnih pojavov v obeh jezikih ustrezna perspektiva vektorskega sistema, ki sta ga za španski jezik razvila španska jezikoslovca Rojo in Veiga.

V obeh jezikih zasledimo tako prvi kot drugi primer dislocirane rabe. $\mathrm{V}$ prvem primeru dislocirane rabe, kakor jo opisujeta Rojo in Veiga, se pri oblikah pribodnjika in pogojnika tako $\mathrm{v}$ španščini kot $\mathrm{v}$ portugalščini pozitivni vektor, ki simbolizira zadobnost, zamenja $\mathrm{z}$ vektorjem za sočastnost, oblika pa pridobi epistemično modalno vrednost izražanja negotovosti, možnosti, predvidevanja. Pri drugem primeru dislocirane rabe pa v obeh jezikih sledimo pojavu, ko oblike pogojnika označujejo časovno razmerje, ki ga v svoji primarni rabi označujejo oblike sedanjika. V procesu dislociranja oblike pogojnika, tako v španščini kot portugalščini, pridobijo modalno vrednost za izražanje neuresničenega, neuresničljivega dejanja. 